\title{
Head insulation and heat loss in the newborn
}

\section{J K STOTHERS}

\author{
The Neonatal Research Group, Physiology Department, London Hospital Medical College
}

SUMMARY The thermal balance of 13 term infants was measured in a closed-circuit metabolism chamber. Each was studied naked, then with a gamgee-lined hat, and finally with a 'cummerbund' made of a similar material and of similar dimensions. At $27^{\circ} \mathrm{C}$ the oxygen consumption of the 'hatted' babies was only $85 \%$ and the total heat loss $75 \%$ of the values measured with the infants naked. The cummerbund offered no detectable benefit. An additional 10 infants were studied while wearing a tubegauze hat at environmental temperatures of $28 \cdot 5( \pm 0 \cdot 5)^{\circ} \mathrm{C}$. This type of hat gave no measurable thermal protection. It is concluded that a substantial reduction of thermal stress in adverse environments can be achieved simply and cheaply by adequately covering the vault of the skull.

The brain of the newborn infant uses a large proportion of the total oxygen consumption $\left(\mathrm{V}_{2}\right)^{12}$ and therefore generates much of the total heat he produces. Due to the fairly high cerebral blood flow, it is likely that most of this heat would be transported to the body, but as the surface area of the head represents $20.8 \%$ of the total body surface area, ${ }^{3}$ heat losses from the head must represent a substantial proportion of the whole. It is to be expected that if the head were insulated by the provision of a hat, heat loss would be lessened, as would be the dangers of hypothermia.

Although Aikens ${ }^{4}$ failed to show any difference in the rate of rectal temperature change in the first hour after birth between babies with and without a tubegauze hat, Chaput de Saintonge et al..$^{5}$ showed that a gamgee-lined woollen hat gave appreciable thermal benefit in the first 30 minutes of life. In both studies the rate of change of rectal temperature was the only measured index of thermal behaviour.

The aims of the present study were to assess more fully the diminution in heat losses when a gamgeelined hat was applied, and to compare this with protection by a pad or cummerbund of similar materials covering a similar area of the lower abdomen. In addition, 'paired' studies of infants naked then wearing a tubegauze hat, similar to those described by Aikens, were undertaken to assess the efficacy of such insulation.*

\section{Methods}

All the studies were performed on well infants from the maternity wards of the London Hospital.

*A preliminary communication was presented to the Neonatal Society in February 1978.

Table 1 Details of the infants studied

\begin{tabular}{|c|c|c|c|c|}
\hline \multirow[t]{2}{*}{ Study } & \multicolumn{2}{|c|}{ Gender } & \multirow{2}{*}{$\begin{array}{l}\text { Weight } \\
(k g)\end{array}$} & \multirow{2}{*}{$\begin{array}{l}\text { Age } \\
\text { (days) }\end{array}$} \\
\hline & Boys & Girls & & \\
\hline $\begin{array}{l}\text { Gamgee hat and cummerbund } \\
(n=13) \\
\text { Range }\end{array}$ & 6 & 7 & $\begin{array}{l}3 \cdot 16 \\
(2 \cdot 76-3 \cdot 66)\end{array}$ & $\begin{array}{l}5 \\
(2-6)\end{array}$ \\
\hline $\begin{array}{l}\text { Tubegauze hat }(n=10) \\
\text { Range }\end{array}$ & 6 & 4 & $\begin{array}{l}3 \cdot 29 \\
(2 \cdot 85-3 \cdot 82)\end{array}$ & $\begin{array}{l}4 \\
(2-6)\end{array}$ \\
\hline
\end{tabular}

Measurements were undertaken only after the informed consent of the mother had been obtained; generally she was present at some time during the study of her baby. Details of the infants are given in Table 1.

The infants were nursed prone in a closedcircuit metabolism chamber, as described by Hill and Rahimtulla ${ }^{6}$ and modified by Hey and Katz. ${ }^{7}$ In the gamgee-lined hat infants, attempts were made to measure each infant at 3 environmental temperatures when naked, and then with abdominal or head protection. Minute-by-minute records of behavioural states, based on the criteria of Prechtl and Beintema, ${ }^{8}$ were made by an experienced observer continuously watching the infant for body and eye movements. Because of the influence of sleep, ${ }^{9}$ position, ${ }^{10}$ feeding, ${ }^{11}$ and activity on $\dot{V}_{2}$, the following criteria had to be met for inclusion in the final analysis: (1) All measurements were made in 'quiet' rapid eye movement sleep. (2) At least 8 minutes of continuous recording were required. (3) Traces made during periods in which the infant made more than one gross body movement in any one minute were excluded. (4) Maintenance of a reasonably constant body position during the observations was required. 
(5) Only measurements made at least one hour after the end of a feed were included.

Because of these strict criteria, paired comparisons proved impossible to obtain and only 23 observations of the infants when naked, 20 when hatted, and 11 wearing a cummerbund were used in the final analysis.

In order to calculate the area covered by the hat, the surface area of the head was assumed to represent $20.8 \%$ of the total body surface area, calculated using Boyd's formula. ${ }^{12}$ Initially, the shape of the head was thought of as a sphere, the maximum circumference being the occipito-frontal circumference (OFC) of the head. Accordingly, the OFCs and weights of 15 infants were carefully measured. When the surface of the head, calculated from the weight of the infant, was compared with the area of the sphere, calculated from the OFC, there was a significant difference $(P<0.001)$, the spherical area being some $20 \%$ less.

The surface area of a cylinder, less one end, was then considered, using a brow-chin length as the height (an underestimate) and the OFC as the circumference (an overestimate). The values obtained conformed more closely with the values calculated using the weight-surface area formula $(\mathrm{P}<0.05)$, the mean difference being $-3.6 \%$. The area left exposed after fitting the hat was then measured horizontally, that is around the face, and vertically. These measurements enabled an approximation of the portion exposed to be calculated. This was found to represent $25 \%$ (SD \pm 3.6$)$ of the total surface area of the head. The appropriate area of abdominal padding, in the form of a rectangle, was therefore $75 \%$ of the surface area of the head.

In all instances rectal temperatures were recorded; where possible, skin temperatures were also recorded, but if skin thermistors became detached, mean skin temperature was calculated using the formula derived by Clark and Stothers. ${ }^{13}$

The operative environmental temperature was calculated from air and wall temperatures weighted according to Gagge's formula. ${ }^{14}$ During each period, minute-by-minute measurements from the traces provided the data for a FORTRAN program written to calculate a mean $\dot{V} \rho_{2}$, standard deviation and standard error in millilitres of oxygen per kilogram per minute, corrected to standard temperature and pressure, dry. It was assumed that one litre of oxygen was equivalent to $4.83 \mathrm{kcal}$. The potential errors in using this figure have been fully discussed by Karlberg. ${ }^{15}$

From the $\dot{\mathrm{Vo}}_{2}$ and heat storage values, calculated from the rectal and skin temperature changes, the total heat loss was obtained. The total evaporative loss was calculated by subtracting the saturation of the inflowing air from the outgoing. Total insulation was then computed using Hey's formula. ${ }^{16}$ All of the formulae used are given in full in the appendix.

The effective surface area, that is the area concerned in insensible heat loss, was calculated by assuming 3 'standard' positions: crouched, mid, and stretched, rendering this area 30,25 , and $20 \%$ less than the total. ${ }^{10}$

A linear relationship between the variables and the rectal-environmental temperature was assumed, permitting a linear regression to be performed in each case. The equation expressing the relationship is expressed in the form $\mathbf{y}=\mathbf{A}+\mathbf{B x}$, where $\mathbf{A}$ is the intercept on the ' $y$ ' axis, and $B$ the slope value of the line. Comparisons of the slopes and intercepts were made using Snedecor's formula. ${ }^{17}$

In the infants wearing tubegauze hats, the same criteria for inclusion were imposed, the same analytical methods used, but readings, naked then hatted, were made at only one environmental temperature $\left(28 \cdot 5^{\circ} \mathrm{C} \pm 0 \cdot 5\right)$. Related $t$ tests were then performed.

\section{Results}

\section{Head and abdominal (gamgee) insulation}

\section{Oxygen consumption}

The results of linear regression of $\dot{\mathrm{Vo}}_{2}$ against rectal-environmental temperature difference $\left(T_{r-e}\right)$ are shown in Fig. 1. The calculations do not include data obtained when $\mathrm{T}_{\mathrm{r}-\mathrm{e}}$ was less than $5^{\circ} \mathrm{C}$, as no diminution in $\mathrm{Vo}_{2}$ would be expected after entry into the thermoneutral range.

Statistical comparison of the slopes (B values) showed no significant difference between the naked and the abdominal pad groups; the hatted infants' values were significantly lower $(P>0.01)$ than either.

Values of $\dot{\mathrm{Vo}}_{2}$ calculated from the regression equations when the rectal-environmental temperature difference was $10^{\circ} \mathrm{C}$ were 7.05 and $8.24 \mathrm{ml} / \mathrm{kg}$ per min for the hatted and naked babies respectively; the insulation was therefore associated with a saving of $14.5 \%$ in $\dot{\mathrm{V}} \mathrm{O}_{2}$.

In addition, linear regression performed with values from the hatted group at rectal-environmental temperature differences of greater than $6.5^{\circ} \mathrm{C}$ showed the slope value $(0.379)$ to be insignificantly different from that of the naked babies when the difference was greater than $5^{\circ} \mathrm{C}$ $(\mathrm{F}=2 \cdot 19, \mathrm{df}=1,27 \mathrm{P}>0 \cdot 05)$, suggesting that the protection offered by the hat reduced the lower limit of the thermoneutral range by some $1.5^{\circ} \mathrm{C}$. 


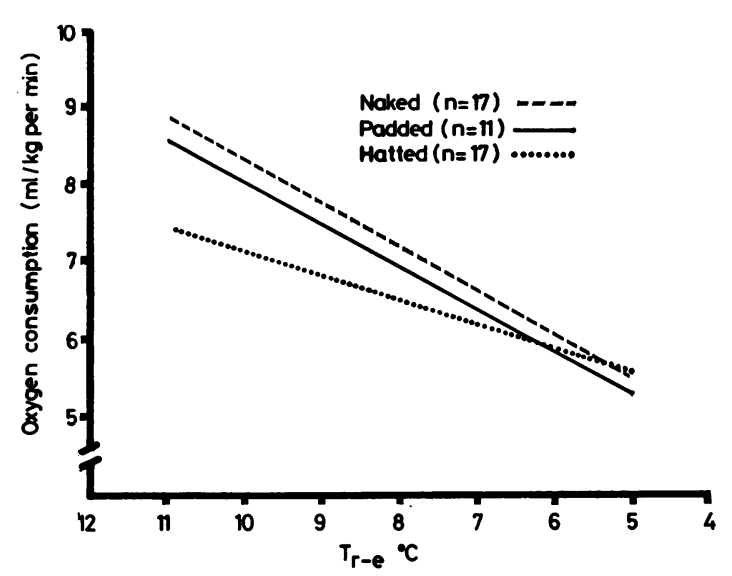

Fig. 1 Linear regressions of the $\dot{V}_{2}$ of the three groups plotted against the rectal-environmental temperature difference. In all cases the regression coefficients are significant at the $1 \%$ level. The respective equations for the naked, hatted, and padded groups are:

$\dot{V} o_{2}=2.72 \pm 0.551\left(T_{\mathrm{r}-\mathrm{e}}\right), \dot{V} o_{2}=4.08 \pm 0.297\left(T_{\mathrm{r}-\mathrm{e}}\right)$, and $\dot{V} o_{2}=2 \cdot 57 \pm 0.544\left(T_{\mathrm{r}-\mathrm{e}}\right)$. In calculating the values, data from infants nursed in thermoneutrality $\left(T_{\mathrm{r}-\mathrm{e}}<5^{\circ} \mathrm{C}\right)$ are excluded (see text).

\section{Heat storage}

Only the naked group had a significant correlation coefficient, when heat storage values were regressed against $T_{r-e}$, rendering statistical comparison invalid although the hatted group had the lowest slope value.

\section{Nonevaporative heat loss}

As no restrictions were imposed on the lower limit of rectal-environmental temperature difference, 23 observations were made of the naked infants, 20 with hats, and 14 with abdominal padding. Linear regressions of the values in each of the groups all had significant coefficients $(P<0 \cdot 01)$. Statistical comparison of the slope values (naked $3 \cdot 49$, hatted $2 \cdot 11$, and padded $3 \cdot 61$ ) showed the only significant difference to be between the hatted infants and the other two groups $(\mathrm{P}<0.01$ in each case). The calculated nonevaporative heat losses at a rectalenvironmental temperature difference of $10^{\circ} \mathrm{C}$ was $28 \cdot 6,36 \cdot 96$, and $37 \cdot 14 \mathrm{~W} / \mathrm{m}^{2}$ for the hatted, naked, and padded groups respectively, the hat therefore being associated with a reduction of dry heat loss of $23 \%$.

\section{Evaporative heat loss}

No significant linear correlation was found with evaporative heat loss and rectal-environmental temperature difference. The overall trend in each of the three groups was for heat loss to diminish with increasing temperature being $7-8 \mathrm{~W} / \mathrm{m}^{2}$ in the thermoneutral zone, and $5.6 \mathrm{~W} / \mathrm{m}^{2}$ in cooler environments.

\section{Total heat loss}

Fig. 2 illustrates the relationships between the three groups.

The results of statistical comparison of the slopes are shown in Table 2.

The calculated loss when naked, at a rectalenvironmental temperature difference of $10^{\circ} \mathrm{C}$, was 42.4 compared with $33.9 \mathrm{~W} / \mathrm{m}^{2}$ when hatted under the same circumstances. The hat therefore saved $25 \%$ of the total heat lost when the environmental temperature was $27^{\circ} \mathrm{C}$, assuming a rectal temperature of $37^{\circ} \mathrm{C}$.

\section{Thermal insulation}

The total insulation of the three groups was calculated, although the results must be treated with

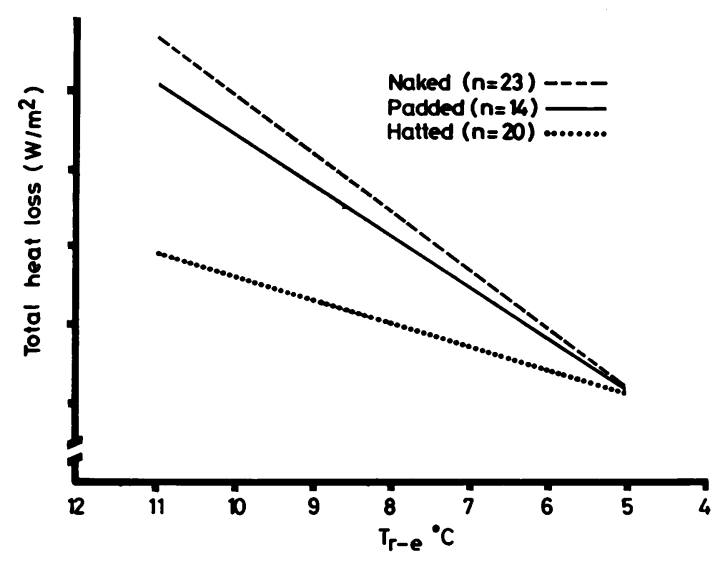

Fig. 2 Linear regression of the total heat loss of the three groups plotted against rectal-environmental temperature difference. As with $\dot{V} o_{2}$, all of the regression coefficients are significant at the $1 \%$ level. The respective equations for the heat loss $\left(\mathrm{W} / \mathrm{m}^{2}\right)$ of the naked, hatted, and padded groups are $8 \cdot 45 \pm 3 \cdot 39\left(T_{\mathrm{r}-\mathrm{e}}\right)$, $17.03+1.69\left(T_{\mathrm{r}-\mathrm{e}}\right)$, and $12.02+3 \cdot 23\left(T_{\mathrm{r}-\mathrm{e}}\right)$.

Table 2 Comparison of the linear regression of total heat loss against $T_{\mathrm{r}-\mathrm{e}}$ slopes, using Snedecor's method, ${ }^{17}$ shows that the pad confers no thermal benefit, and that hatted infants lose significantly less heat than either of the other two groups

\begin{tabular}{lrll}
\hline & $F$ value & Degree of freedom & Significance \\
\hline Hat: naked & 26.356 & 1,39 & $<0.01$ \\
Pad: naked & 0.046 & 1,33 & NS \\
Hat: pad & 6.185 & 1,30 & $<0.01$ \\
\hline
\end{tabular}


Table 3 Results of 'paired' studies of infants naked and wearing a tubegauze hat

\begin{tabular}{lcc}
\hline & Naked & Gauze hat \\
\hline Dry heat loss $\left(\mathrm{W} / \mathrm{m}^{2}\right)$ & $28.40(3.64)$ & $30.64(2.94)$ \\
Evaporative heat loss $\left(\mathrm{W} / \mathrm{m}^{2}\right)$ & $7.48(1.63)$ & $6.84(1.68)$ \\
Total heat loss $\left(\mathrm{W} / \mathrm{m}^{2}\right)$ & $35.88(3.71)$ & $37.48(3.06)$ \\
Total insulation $\left({ }^{\circ} \mathrm{Cm}^{2} / \mathrm{W}\right)$ & $0.190(0.015)$ & $0.193(0.012)$ \\
\hline
\end{tabular}

some reserve. As already stated, some calculations include a calculated mean skin temperature. Again, the regressions do not include data obtained when $\mathrm{T}_{\mathrm{r}-\mathrm{e}}$ was less than $5^{\circ} \mathrm{C}$. The correlation coefficients of the naked, hatted, and padded groups were somewhat poorer than in the previous partitional calculations $(r \simeq 0.05$ in each case). However, from the equations, the total insulation when naked with a rectal-environmental temperature difference of $10^{\circ} \mathrm{C}$ would be $0 \cdot 192^{\circ} \mathrm{C} \mathrm{W} / \mathrm{m}^{2}$, and with a hat $0.233^{\circ} \mathrm{C} \mathrm{W} / \mathrm{m}^{2}$, an increase of some $21 \%$.

\section{Gauze hat series}

Mean values (with standard deviations) of the 10 infants studied naked, then wearing tubegauze hats are given in Table 3. The tubegauze hat would appear to be associated with an insignificant increase in total insulation of only some $2 \%$.

\section{Discussion}

Consideration of the results of studies of the gamgee hatted infants raises two interesting physiological points. The $\dot{\mathrm{V}}_{2}$ of the infants wearing a hat was $14.5 \%$ less than that of the naked group at an environmental temperature of about $27^{\circ} \mathrm{C}$. If the head represents $20.8 \%$ of the total surface area and $75 \%$ of this is covered by the hat, then the portion exposed will be $15.6 \%$ of the total body surface area. The obvious similarity between the percentage covered and the percentage decrease in $\dot{V} o_{2}$ supports the suggestion that there is a fairly direct relationship between the area exposed to cooling and the $\dot{\mathrm{V}}_{2}$, or chemical response. That this should be true of the head is in contrast to the suggestion of Froese and Burton ${ }^{18}$ that it was not a particularly thermosensitive area in the adult. This was based on the observation that we may expose our heads to a cool environment without feeling cold, a point which they felt was supported by Burton's finding ${ }^{19}$ that the head has a fairly high and constant skin temperature, and that the arterial supply to the forehead is little affected by cooling. Burton's temperature measurements were also made on the forehead, an area unique in its nervous supply, and perhaps unrepresentative of the rest of the head in its thermal response.
The apparent absence of effect of lower abdominal insulation was almost certainly due to two factors. With the infants nursed prone, only the lower back was 'protected', although it must also be noted that a portion of the 'hatted' head would be further insulated by contact with the mattress. It has been demonstrated thermographically ${ }^{20}$ that the lower trunk is not one of the hotter areas of the body, having no underlying thermogenic organs, and would consequently lose less heat than an area such as the head. In addition, inter-infant variability would mask minor differences, especially in a fairly small series.

Respiratory calorimetry renders thermal balance calculations highly dependent on changes in heat storage and evaporative losses. The strict criteria used in the final analysis-such as sleep state, position, postprandial state, and absence of movement allowed only short periods of observation. Transient fluctuations in rectal temperature or water loss may well have been responsible for the lack of correlation of these variables. The effect of the hat on mean skin temperatures is unknown, but must be considerable. Similarly, the effect of the hat on evaporative losses is not predictable. However, the total calculated heat losses appear reasonable. The naked infants, in thermoneutrality, had an evaporative heat loss of about $7 \mathrm{~W} / \mathrm{m}^{2}$ representing $27 \%$ of the total heat loss of $25.5 \mathrm{~W} / \mathrm{m}^{2}$. This figure is only slightly higher than that found by Hey and $\mathrm{Katz}^{7}$ of $23 \%$. The higher $\dot{\mathrm{V}}_{2}$ values recorded in their series, due possibly to movement, etc., probably account for the decreased ratio.

The clinical importance of these findings is obvious. Hypothermia is still common during the neonatal period. Apart from accidental hypothermia associated with the actual birth, surgical and investigative manoeuvres often necessitate fairly extensive and prolonged exposure; low rectal temperatures are common after such procedures. A tubegauze hat offers little protection, but heat loss can be substantially reduced by covering the vault of the skull with a gamgee-lined woollen hat.

\section{Appendix}

Formulae used in the various calculations.

Surface area ${ }^{12}$ (A)

$\mathrm{A}=4 \cdot 688^{*} \mathrm{~W}^{(0.8168-0.01541 \mathrm{gW})} * 10^{-4}$

when $A$ is in $m^{2}$, and $W$ the weight of the infant in grams.

Mean skin temperature $\mathrm{e}^{13}\left(\mathrm{~T}_{\overline{\mathrm{s}}}\right)$

$\mathrm{T}_{\mathrm{s}}^{-}=36.03-0.203 *\left(\mathrm{~T}_{\mathrm{r}}-\mathrm{T}_{\mathrm{e}}\right)$ 
when $T_{\bar{s}}^{-}$is in ${ }^{\circ} \mathrm{C}$ as are the rectal $\left(T_{r}\right)$ and environmental $\left(T_{e}\right)$ temperatures.

Operative environmental temperature ${ }^{14}\left(\mathrm{~T}_{\mathrm{e}}\right)$

$\mathrm{T}_{\mathrm{e}}=0.4 \mathrm{~T}_{\mathrm{a}}+0.6 \mathrm{~T}_{\mathrm{w}}$

when $T_{e}$ is in ${ }^{\circ} \mathrm{C}$ as are the air $\left(T_{a}\right)$ and wall $\left(T_{w}\right)$ temperatures.

Heat storage ${ }^{16}(\mathrm{HS})$

$\mathrm{HS}=\mathrm{W}\left(\left(0.7 \triangle \mathrm{T}_{\mathrm{r}}\right)+\left(0.3 \Delta \mathrm{T}_{\mathrm{s}}\right)\right)^{*} 3.47$

when HS is in watts, $W$ is the weight of the infant in $\mathrm{kg}, \Delta \mathrm{T}_{\mathrm{r}}$ and $\Delta \mathrm{T}_{\overline{\mathrm{s}}}$ are the rectal and mean skin temperature changes in ${ }^{\circ} \mathrm{C}$ hour, and 3.47 is the specific heat of the body ${ }^{21}$ in $\mathrm{kJ} / \mathrm{kg}{ }^{\circ} \mathrm{C}$.

Total insulation ${ }^{15}(\mathrm{I})=$ tissue insulation $\left(\mathrm{I}_{\mathrm{t}}\right)+$ ambient insulation $\left(I_{a}\right)$

$I_{t}=A\left(T_{r}-T_{s}\right) H_{C R}+H_{E s}$ and $I_{a}=A\left(T_{s}-T_{e}\right) / H_{C R}$ when $I_{t}$ and $I_{a}$ are in ${ }^{\circ} \mathrm{C} \mathrm{m} / \mathrm{W}, A$ is the surface area in $m^{2}, T_{r}, T_{e}$, and $T_{\bar{s}}$ are the rectal, environmental, and mean skin in ${ }^{\circ} \mathrm{C}$. $\mathrm{H}_{\mathrm{CR}}$ is the 'dry' heat loss and $\mathrm{H}_{\mathrm{Es}}$ the evaporative losses, both in watts.

I thank Professor K W Cross for his advice and encouragement, Miss Ruth Warner for expert technical assistance, the medical and nursing staff of the maternity wards of The London Hospital, and the mothers who allowed their infants to be studied.

This work was supported by The Wellcome Trust and Vickers Medical Limited.

\section{References}

1 Cross K W, Stratton D. Aural temperature of the newborn infant. Lancet 1974 ; ii: $1179-80$.

2 Stratton D. Aural temperature of the newborn infant. Arch Dis Child 1977; 52: 865-9.

3 Klein A D, Scammon R E. The regional growth of the surface area of the human body in prenatal life. Proc Soc Exp Med Biol 1930; 27: 463-6.

4 Aikens $R$ M. Hats and lamps in the prevention of neonatal hypothermia. Nursing Mirror 1977; 144: 65-6.

5 Chaput de Saintonge D M, Cross K W, Hathorn M K S, Lewis $\mathbf{S} \mathbf{R}$, Stothers $\mathbf{J}$ K. Hats for the newborn infant. Br Med J 1979; ii: 570-1.
6 Hill J R, Rahimtulla K A. Heat balance and the metabolic rate of newborn babies in relation to environmental temperature; and the effect of age and of weight on basal metabolic rate. J Physiol (Lond) 1965 ; 180 : 239-65.

7 Hey E N, Katz G. Evaporative water loss in the newborn baby. J Physiol (Lond) 1969; 200: 605-19.

8 Prechtl H F R, Beintema D. The neurological examination of the full-term newborn infant. Little Club Clinics in Developmental Medicine No 12. London: Heinemann, 1964: 12.

9 Stothers J K, Warner R M. Oxygen consumption and neonatal sleep states. J Physiol (Lond) 1979; 278: 435-40.

10 Stothers J K. Indirect measurement of the output of heat from the brain of the newborn. PhD thesis, University of London 1979.

11 Stothers J K, Warner R M. Effect of feeding on neonatal oxygen consumption. Arch Dis Child 1978; 54: 415-20.

12 Boyd E. The growth of the surface area of the human body. Minneapolis: University of Minnesota Press, 1935: $100-2$.

13 Clark R P, Stothers J K. Neonatal skin temperature distribution using infra-red colour thermography. J Physiol (Lond) 1980 ; 302 : 323-33.

14 Gagge A P. Standard operative temperature, a generalized temperature scale, applicable to direct and partitional calorimetry. Am J Physiol 1940; 131 : 93-103.

15 Karlberg P. Determination of standard energy metabolism (basal metabolism) in normal infants. Acta Paediatr Scand [Suppl] 1952; 41 : Supplement 89, 73.

16 Hey E N, Katz G, O'Connell B. The total thermal insulation of the newborn baby. J Physiol (Lond) 1970; 207: 683-98.

17 Snedecor G W, Cochran W G. Statistical methods. Iowa: Iowa State University Press, 1967: 432-6.

18 Froese G, Burton A C. Heat losses from the human head. J Appl Physiol 1957; 10: 235-41.

19 Burton A C. A new technic for the measurement of average skin temperature over surfaces of the body and the changes of skin temperature during exercise. $J$ Nutr 1934; 7: 481-95.

20 Clark R P, Cross K W, Goff $M$ R, Mullan B J, Stothers J K, Warner R M. Neonatal whole-body thermography. J Physiol (Lond) 1978; 280: 2-3P.

21 Burton A C, Edholm O G. Man in a cold environment. London: Arnold, 1955: 41-2.

Correspondence to Dr J K Stothers, Physiology Department, London Hospital Medical College, Turner Street, London E1 2AD.

Received 12 May 1980 